\title{
Natural History of Growth Hormone Deficiency in a Pediatric Cohort
}

\author{
Eva Deillon $^{\mathrm{a}}$ Michael Hauschild ${ }^{\mathrm{a}}$ Mohamed Faouzi $^{\mathrm{b}}$ Sophie Stoppa-Vaucher ${ }^{\mathrm{a}}$ \\ Eglantine Elowe-Gruau ${ }^{a}$ Andrew Dwyer ${ }^{c}$ Gerald E. Theintz ${ }^{a}$ \\ Jean-Michel Dubuis ${ }^{d}$ Primus E. Mullis ${ }^{\text {e Nelly Pitteloud }}{ }^{\mathrm{a}, \mathrm{c}}$ Franziska Phan-Hug ${ }^{\mathrm{a}}$ \\ a Division of Endocrinology, Diabetology and Obesity, Department of Pediatrics, and ${ }^{\mathrm{b} C e n t e r}$ of Clinical Epidemiology, \\ University Hospital Lausanne, and ' Department of Endocrinology, Diabetology and Metabolism (EDMD), Centre \\ Hospitalier Universitaire Vaudoise (CHUV), Lausanne, d Groupe Médical du Grand-Lancy, Geneva, and ${ }^{e}$ Division of \\ Pediatric Endocrinology, Diabetology and Metabolism and Department of Clinical Research, University Children's \\ Hospital, Inselspital, Bern, Switzerland
}

\section{Key Words}

Growth hormone deficiency · Growth hormone · IGF-1 .

Transition · Predictors

\begin{abstract}
Background/Aims: Controversies still exist regarding the evaluation of growth hormone deficiency (GHD) in childhood at the end of growth. The aim of this study was to describe the natural history of GHD in a pediatric cohort. Methods: This is a retrospective study of a cohort of pediatric patients with GHD. Cases of acquired GHD were excluded. Univariate logistic regression was used to identify predictors of GHD persisting into adulthood. Results: Among 63 identified patients, 47 (75\%) had partial GHD at diagnosis, while 16 (25\%) had complete GHD, including 5 with multiple pituitary hormone deficiencies. At final height, 50 patients underwent repeat stimulation testing; 28 (56\%) recovered and 22 (44\%) remained growth hormone (GH) deficient. Predictors of persisting GHD were: complete GHD at diagnosis (OR 10.1, 95\% Cl 2.4-42.1), pituitary stalk defect or ectopic pituitary gland on magnetic resonance imaging (OR 6.5, 95\% Cl 1.1-37.1), greater height gain during $\mathrm{GH}$ treatment (OR 1.8, 95\% Cl 1.03.3), and IGF-1 level <-2 standard deviation scores (SDS) following treatment cessation (OR 19.3, 95\% Cl 3.6-103.1). In
\end{abstract}

the multivariate analysis, only IGF-1 level <-2 SDS (OR 13.3, $95 \% \mathrm{Cl} 2.3-77.3)$ and complete GHD (OR 6.3, 95\% Cl 1.2-32.8) were associated with the outcome. Conclusion: At final height, $56 \%$ of adolescents with GHD had recovered. Complete GHD at diagnosis, low IGF-1 levels following retesting, and pituitary malformation were strong predictors of persistence of GHD.

(c) 2015 S. Karger AG, Basel

\section{Introduction}

Among children presenting with short stature, approximately $10 \%$ have pathologic growth hormone deficiency (GHD) [1]. The diagnosis of GHD is based on clinical presentation and results of dynamic testing [2,3]. Growth hormone $(\mathrm{GH})$ replacement therapy is an effective treatment in these children. Continuing GH treatment at the end of growth remains a clinically important question since $\mathrm{GH}$ is also available for adults [4]. Beneficial effects of GH treatment in adults include: increased periosteal bone formation and muscle mass, decreased fat mass, improved lipid profile and psychological well-being [5-10]. However, possible negative effects of GH treatment include: increased insulin resistance, fluid retention with occasional edema,

\section{KARGER 125}

(c) 2015 S. Karger AG, Base

$1663-2818 / 15 / 0834-0252 \$ 39.50 / 0$

E-Mail karger@karger.com

www.karger.com/hrp
Franziska Phan-Hug, MD

Division of Endocrinology, Diabetology and Obesity

Department of Paediatrics, University Hospital

Chemin de Montétan 16, CH-1000 Lausanne (Switzerland)

E-Mail franziska.phan-hug@ chuv.ch 
Table 1. Thresholds for diagnosing GHD at final height

\begin{tabular}{|c|c|c|c|c|c|}
\hline Authors [Ref.], year & $\begin{array}{l}\text { Time of } \\
\text { reassessment }\end{array}$ & ITT & $\begin{array}{l}\text { GHRH-ARG } \\
\text { test }\end{array}$ & ARG test & IGF-1 level \\
\hline $\begin{array}{l}\text { Growth Hormone } \\
\text { Research Society, } 1998\end{array}$ & adulthood & $<3.0 \mu \mathrm{g} / \mathrm{l}$ & none given & none given & none given \\
\hline Biller et al. [16], 2002 & adulthood & $\begin{array}{l}<5.0 \mu \mathrm{g} / \mathrm{l} ; \\
\text { sensitivity 95\%; } \\
\text { specificity } 92 \%\end{array}$ & $\begin{array}{l}<4.1 \mu \mathrm{g} / \mathrm{l} ; \\
\text { sensitivity } 95 \% \\
\text { specificity } 91 \%\end{array}$ & $\begin{array}{l}<1.4 \mu \mathrm{g} / \mathrm{l} ; \\
\text { sensitivity } 95 \% ; \\
\text { specificity } 62 \%\end{array}$ & $\begin{array}{l}<-2 \text { SDS; } \\
\text { sensitivity } 46 \% \\
\text { specificity } 100 \%\end{array}$ \\
\hline Maghnie et al. [18], 2005 & at transition & $\begin{array}{l}<6.1 \mu \mathrm{g} / \mathrm{l} ; \\
\text { sensitivity } 96 \% \\
\text { specificity } 100 \%\end{array}$ & none given & none given & $\begin{array}{l}<-1.7 \text { SDS; } \\
\text { sensitivity } 77 \% \\
\text { specificity } 100 \%\end{array}$ \\
\hline Corneli et al. [19], 2007 & at transition & none given & $\begin{array}{l}<19.0 \mu \mathrm{g} / \mathrm{l} ; \\
\text { sensitivity } 100 \% \text {; } \\
\text { specificity } 97 \%\end{array}$ & none given & none given \\
\hline
\end{tabular}

Previously published stimulation tests with respective cutoff values of GH ( $\mu \mathrm{g} / \mathrm{l})$. ITT and GHRH-ARG test demonstrated the best sensitivity and specificity for evaluating GHD following treatment (final height).

pseudotumor cerebri, and carpal tunnel syndrome $[9,11]$. Furthermore, there are growing concerns about the longterm effects of GH treatment with recent reports of an increased risk of cardiovascular events, especially hemorrhagic stroke in adults treated with GH during childhood [12-14]. For childhood-onset GHD, the transition period from adolescence to adulthood represents a critical time for reassessing $\mathrm{GH}$ status. At completion of growth (defined by bone age $>14$ years in girls and $>16$ years in boys or growth velocity $<2 \mathrm{~cm} /$ year), about $40 \%$ of patients remain $\mathrm{GH}$ deficient in adulthood [15]. Importantly, as summarized in table 1, there is yet no consensus regarding the evaluation of GHD in adolescents at the end of growth in order to define which patients will benefit from continued GH treatment despite a variety of protocols and proposed thresholds to address this question [2,11,15-19].

Therefore, this study aimed to describe the natural history of GHD in a cohort of adolescents during the transition period and to identify predictors of GHD continuing into adulthood.

\section{Research Design and Methods}

We studied a cohort of children with GHD who were treated at the University Hospital of Lausanne from 1998 to 2011. Adolescents who completed growth with bone age $>14$ years in girls and $>16$ years in boys or growth velocity $<2 \mathrm{~cm} /$ year were included.
Cases of acquired GHD (i.e. trauma or oncology treatments) and individuals receiving $\mathrm{GH}$ for other indications (i.e. Turner syndrome, small for gestational age, SHOX gene haploinsufficiency, and chronic renal insufficiency) were excluded.

The diagnosis of GHD was based on the results of two provocation tests [insulin tolerance test (ITT), arginine (ARG) test, or glucagon test with peak $\mathrm{GH}<10 \mu \mathrm{g} / \mathrm{l}]$ or one pathological test associated with structural pituitary abnormalities such as hypoplasia, stalk defect, or ectopic posterior pituitary on magnetic resonance imaging (MRI) [3]. Priming with sex steroids was used before the stimulation test in prepubertal children $>10$ years of age. GH treatment was conducted in a dose-dependent manner $(0.15-0.20 \mathrm{mg}$ / $\mathrm{kg} /$ week) to normalize IGF-1 levels [between -2 and 2 standard deviation scores (SDS)].

At completion of growth, GH status was reassessed by dynamic testing and by serum IGF-1 measurement following a GH treatment cessation (1-4 months). The ARG test was proposed in the majority of cases because of better tolerance compared to other tests [16]. Adolescents with multiple $(>2)$ pituitary hormone [GH, adrenocorticotropic hormone (ACTH), luteinizing hormone ( $\mathrm{LH})$, follicle stimulating hormone (FSH), or thyroid-stimulating hormone (TSH)] deficiencies [20, 21] were considered GH deficient without retesting and $\mathrm{GH}$ treatment was continued into adulthood without interruption.

We defined complete GHD as a peak GH $<5 \mu \mathrm{g} / \mathrm{l}$ and partial GHD as a peak $\mathrm{GH} \geq 5-10 \mu \mathrm{g} / \mathrm{l}$ following stimulation at diagnosis and at final height, as proposed in prior studies $[15,17]$. The decision to continue GH treatment was based on the 1998 Growth Hormone Research Society recommendations (peak GH of $<3 \mu \mathrm{g} / \mathrm{l}$ ) [11]. The study was approved by the local ethics committee.

$\mathrm{GH}$ concentrations were determined using a chemiluminescent immunoassay (CIA) with a System Luminometer 400 (Nich- 
ols Institute Diagnostics, Bad Nauheim, Germany; study period 1998-2004). The CIA assay has an analytical sensitivity of $0.2 \mu \mathrm{g} / \mathrm{l}$ with an intra-assay coefficient of variation (CV) of $4.0-5.4 \%$ and an inter-assay CV of 7.9-9.2\%. From 2004 on, the automated CIA Immulite 2000 (Siemens Healthcare Diagnostics Inc., Erlangen, Germany) was used with an analytical sensitivity of $0.05 \mu \mathrm{g} / \mathrm{l}$, an intra-assay CV of 2.9-4.6\%, and an inter-assay CV of $4.2-6.6 \%$. The GH calibration standard used for both platforms was the WHO NIBSC (1st 80/505 until December 2009 and 2nd 98/574 thereafter). IGF-1 concentrations were determined by a radioimmunoassay from Nichols Institute Diagnostics (study period 1998-2005). The radioimmunoassay had an analytical sensitivity of $15 \mu \mathrm{g} / \mathrm{l}$, an intra-assay CV of $2.4-3.0 \%$, and an inter-assay CV of $5.2-8.4 \%$. From 2005 on, the automated CIA Immulite 2000 (Siemens Healthcare Diagnostics Inc.) was used. The automated assay has an analytical sensitivity of $35 \mu \mathrm{g} / \mathrm{l}$, an intra-assay CV of 2.3$3.9 \%$, and an inter-assay CV of $3.7-8.1 \%$. The WHO NIBSC 1 st IRR $87 / 518$ was used for IGF-1 calibration throughout the entire study period. IGF-1 data were transformed into sex- and age-related SDS values using previously published data [22].

\section{Statistical Analysis}

Data are presented as means \pm standard deviations (SD). Categorical data are presented using descriptive statistics. Predictors of persisting GHD were examined using logistic regression analysis. The strength of the association measured by the odds ratio (OR) and significant predictors at the level of 5\% from the univariate analysis were used in a forward procedure to fit a multivariate model. Confirmation of OR results included nonparametric bootstrap analysis (replication $\times 100$ ). Data analysis was performed using STATA-12 software (Stata Statistical Software, release 12, StataCorp 2011, College Station, Tex., USA).

\section{Results}

One hundred and sixty-two children with GHD were treated at the University Hospital of Lausanne between 1998 and 2011, 82 of whom had completed their growth. Of these 82 patients, 19 (23\%) had acquired forms of GHD and were excluded, while the remaining 63 adolescents with congenital or idiopathic GHD (77\%) were included in the analysis.

\section{Characteristics of the GH-Deficient Cohort at Diagnosis}

Three quarters of the cohort (47/63) exhibited partial GHD (75\%), while 16/63 had complete GHD (25\%) (fig. 1). In total, 42 (67\%) were boys and 21 (33\%) girls. The diagnosis was made at a mean age of $9.5 \pm 3.6$ years. The mean height was $-2.4 \pm 0.7$ SDS at diagnosis with a delayed bone age of $2.2 \pm 1.1$ years. Twenty subjects (20/63) exhibited pituitary malformation (32\%) including 11/20 with complete GHD (55\%) and 9/20 with partial GHD (45\%) at diagnosis (fig. 1). Six boys and 2 girls
( $>10$ years of age) were diagnosed with partial GHD after priming with sex steroids. Clinical, radiologic, and biochemical characteristics of subgroups (partial GHD, $\mathrm{n}=$ 47 , and complete GHD, $\mathrm{n}=16$ ) are presented in table 2. All patients with partial GHD had isolated GHD, while patients with complete GHD included 5 children with multiple pituitary hormone deficiencies (MPHD). Three children had $>2$ pituitary hormone deficiencies associated with SOD $(\mathrm{n}=1)$ and ectopic posterior pituitary gland $(n=2)$. The 2 other children with MPHD included 1 girl with TSH and GH deficiencies associated with stalk defect and ectopic posterior pituitary gland on MRI and 1 boy with GH and LH/FSH deficiency as well as pituitary hypoplasia (table 2 ).

\section{GH Reassessment at Final Height}

At final height, 50/63 children were retested for GHD (fig. 1). Three patients with MPHD were considered GH deficient without treatment interruption and were integrated into statistical analyses as GH deficient. The other 10 were lost to follow-up. The vast majority of patients (47/50) underwent ARG testing, while 2 had an ARG-ITT test and 1 an ITT. Nine out of $50(18 \%)$ patients showed complete GHD, 13/50 (26\%) partial GHD, and 28/50 (56\%) recovered. The rate of reversal (according to different cutoffs) among the diagnostic subgroups is presented in figure 1 . Seven of the 63 patients in this cohort continued GH treatment into adulthood: 4 had a peak $\mathrm{GH}<3 \mu \mathrm{g} / \mathrm{l}$ and an IGF-1 level $<-2$ SDS and 3 patients with MPHD $(>2)$ were considered GH deficient at adulthood (fig. 1).

\section{GH Reassessment of Patients with Partial GHD at} Diagnosis

Of the 47 patients with partial GHD at initial diagnosis, 37 had repeat stimulation testing at final height (fig. 1). In total, 25/37 (68\%) patients recovered, 9/37 (24\%) patients remained with partial GHD, and 3/37 (8\%) patients worsened to complete GHD (fig. 1, 2). Importantly, no adolescent initially diagnosed with partial GHD had a GH peak $<3 \mu \mathrm{g} / \mathrm{l}$ and none of these patients continued GH treatment into adulthood. The 3 adolescents who had worsening deficiency with complete GHD at final height had a peak GH between 3 and $5 \mu \mathrm{g} / \mathrm{l}$. Two had an IGF-1 level >-2 SDS and no pituitary abnormalities on MRI, while 1 patient exhibited ectopic posterior pituitary on MRI at final height.

Four of the 9 children that remained partially GH deficient showed IGF-1 levels $<-2$ SDS. One had pituitary hypoplasia. Of the 25/37 patients who recovered from partial GH deficiency, 3 had pituitary malformations (2 


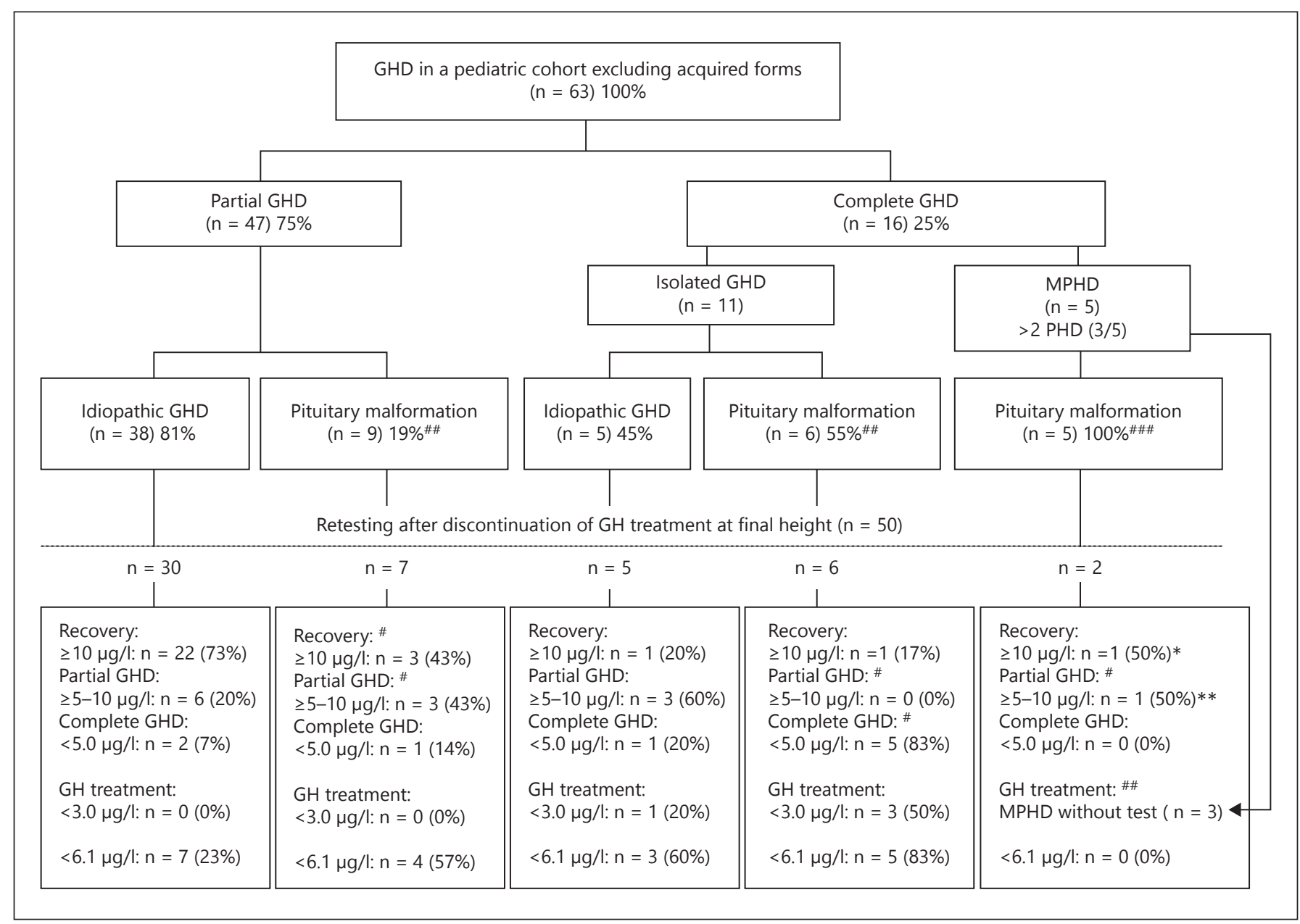

Fig. 1. Diagnostic subgroups of childhood-onset GHD at diagnosis and at the end of GH treatment (final height) using different cutoffs. Pituitary malformation includes pituitary hypoplasia, stalk defect, or ectopic posterior pituitary. MPHD includes $>2$ pituitary hormone deficiencies $(n=3)$. Patients with $>2$ pituitary hormone

with hypoplasia and 1 with ectopic posterior pituitary), while IGF-1 levels were $\geq-2$ SDS. The other 22 patients without pituitary anomalies had idiopathic GHD (88\%). Two of these children had IGF-1 levels $<-2$ SDS but a GH peak $>20 \mu \mathrm{g} / \mathrm{l}$ (fig. 1).

\section{GH Reassessment of Patients with Complete GHD at} Diagnosis

Thirteen of the 16 patients had a stimulation test at final height (fig. 1). Nearly half of the patients remained with complete GHD after stimulation $(6 / 13,46 \%)$, while 4/13 (31\%) patients improved to partial GHD and 3/13 (23\%) patients recovered (fig. 1, 2). Three patients with MPHD were considered GH deficient without testing.

Natural History of Growth Hormone Deficiency deficiencies $(n=3)$ were not retested but considered GH deficient and included in the statistical analysis (arrow). PHD = Pituitary hormone deficiencies. ${ }^{*} \mathrm{GH}$ and LH/FSH deficiencies $(\mathrm{n}=1)$; ** GH and TSH deficiencies $(\mathrm{n}=1)$; ${ }^{*}$ patients with ectopic pituitary gland ( $\mathrm{n}$ of symbols $=\mathrm{n}$ of patients).

One of the children with complete GHD (peak GH level $3.3 \mu \mathrm{g} / \mathrm{l}$ after ARG test) was not treated as the peak GH was $>3 \mu \mathrm{g} / 1$ [11]. This child had ectopic posterior pituitary on MRI but exhibited IGF-1 levels >-2 SDS after treatment interruption.

Two adolescents who improved to partial GHD had IGF-1 $<-2$ SDS. One had idiopathic GHD, while the other had stalk defect and ectopic posterior pituitary. In addition, the latter had MPHD ( $\mathrm{GH}$ and TSH). One of the 3 children with recovery showed MPHD (GH and FSH/ $\mathrm{LH}$ ) associated with pituitary hypoplasia and severe obesity. Following puberty induction and weight loss, this adolescent recovered from GHD and gonadotropin deficiency. The 2 others had isolated GHD (fig. 1, 2). 
Fig. 2. GH peak response to stimulation testing at the end of treatment (final height) in patients with complete GHD (grey) and partial GHD (white) at diagnosis in childhood. Complete GHD defined by peak GH $<5 \mu \mathrm{g} / \mathrm{l}$. Partial GHD defined by peak GH $\geq 5-10 \mu \mathrm{g} / \mathrm{l}$. Recovery of GHD defined by peak $\mathrm{GH}>10 \mu \mathrm{g} / \mathrm{l}$ at stimulation.

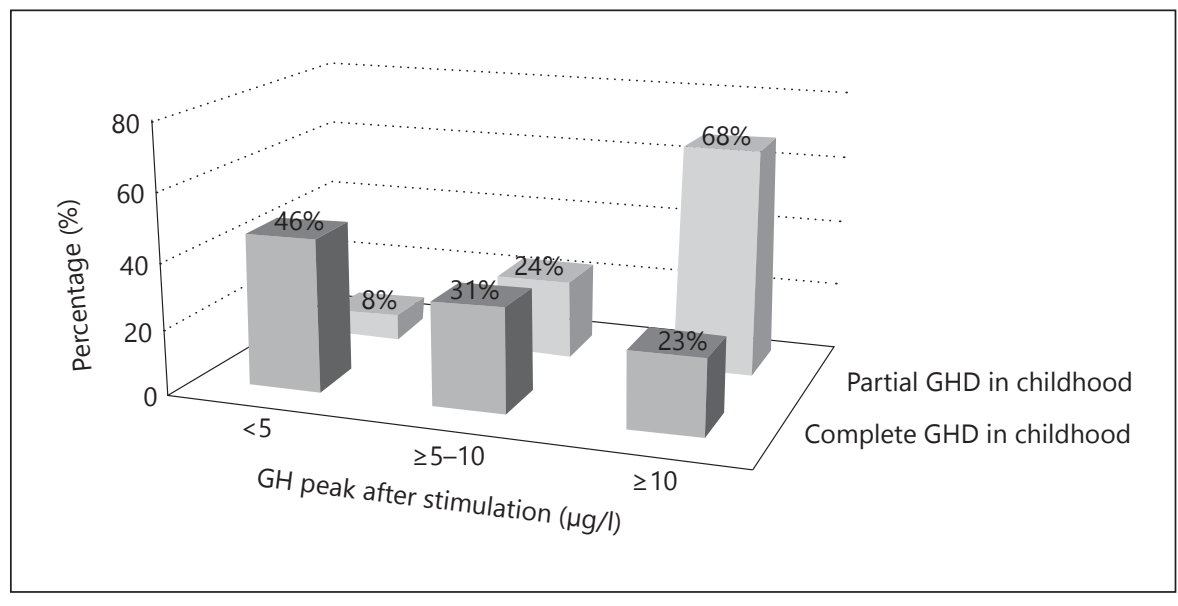

GH Reassessment According to Pituitary Anomalies at Diagnosis

At final height, 15/20 young patients with pituitary anomalies at diagnosis were reevaluated by stimulation test, and 3 children with MPHD were considered GH deficient (fig. 1). Among the patients with pituitary malformation, 5 (33\%) recovered, including 1 out of 5 retested patients with ectopic posterior pituitary gland. Only 1 patient with ectopic posterior pituitary gland showed a GH peak $<5 \mu \mathrm{g} / \mathrm{l}$ (fig. 1). In our series, $35 \mathrm{pa}-$ tients had no pituitary malformation. Of those, 23 (66\%) recovered.

\section{IGF-1 Reassessment at Final Height after Treatment} Interruption

Plasma IGF-1 levels after treatment interruption were measured in 52/63 adolescents. In 14 adolescents, IGF-1 levels were $<-2$ SDS at reevaluation (table 2 ). Two adolescents who showed IGF- 1 levels $<-2$ SDS recovered. These 2 children showed no pituitary malformation and peak GH levels at reassessment of $>20 \mu \mathrm{g} / \mathrm{l}$.

\section{Predictors of Persisting GHD at Final Height}

We evaluated several factors predicting the persistence of GHD into adulthood (table 3). Positive predictors included: (1) IGF-1 levels <-2 SDS following discontinuation of GH treatment (OR 19.3); (2) complete GHD at diagnosis in childhood (OR 10.1); (3) pituitary malformation at diagnosis (OR 5.6), especially stalk defect and/ or ectopic posterior pituitary (OR 6.5), and (4) height gain of 1 SDS on treatment (OR 1.8). Data are summarized in table 3.

When multivariate logistic regression was used, only complete GHD at diagnosis and an IGF-1 level $<-2$ SDS
Table 2. Clinical, radiologic, and biochemical characteristics of 63 children with childhood-onset GHD divided into diagnostic subgroups

\begin{tabular}{lll}
$\begin{array}{l}\text { Partial/ } \\
\text { isolated }\end{array}$ & \multicolumn{2}{l}{ Complete GHD $(\mathrm{n}=16)$} \\
\cline { 2 - 3 } $\begin{array}{l}\text { GHD } \\
(\mathrm{n}=47)\end{array}$ & isolated & MPHD \\
& GHD & $(\mathrm{n}=5)$
\end{tabular}

Clinical and radiological characteristics at diagnosis
Age, years

Sex ratio, $\mathrm{f} / \mathrm{m}$

Height SDS

BMI SDS

Delayed bone age, years

Pituitary on MRI

Hypoplasia/aplasia

Stalk defect

Ectopic posterior pituitary

Septo-optic dysplasia

$\begin{array}{ccc}9.5 \pm 3.6 & 9.0 \pm 4.7 & 9.5 \pm 7.4 \\ 17 / 30 & 2 / 9 & 2 / 3 \\ -2.4 \pm 0.6 & -2.7 \pm 0.8 & -2.1 \pm 1.3 \\ -0.2 \pm 2.1 & 0.7 \pm 2.0 & 3.7 \pm 3.5 \\ 2.1 \pm 1.06 & 2.5 \pm 1.6 & 2.1 \pm 1.2 \\ (\mathrm{n}=38) & & \end{array}$

$(\mathrm{n}=38)$

6
3
2
0

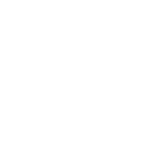

Clinical and biochemical characteristics at final height (cessation of GH treatment)

$\begin{array}{lccc}\text { Age, years } & 16.6 \pm 1.3 & 16.8 \pm 1.9 & 18.0 \pm 2.1 \\ \text { Final height SDS } & -0.89 \pm 0.7 & -0.7 \pm 1.8 & 0.1 \pm 1.5 \\ \text { Height gain SDS } & 1.47 \pm 0.7 & 1.99 \pm 1.38 & 2.19 \pm 2.13 \\ \text { IGF-1 <-2 SDS, n/total n } & 6 / 38 & 6 / 11 & 2 / 3\end{array}$

Values are means \pm SD or numbers, unless otherwise indicated.

following GH treatment cessation were significant as independent positive predictors. Furthermore, when these two factors were combined, the sensitivity and specificity was the highest. The obtained Hosmer-Lemeshow test of goodness-of-fit $\mathrm{p}$ value was 0.68 and the area under the ROC curve was 0.81 (fig. 3 ). 
Table 3. Predictors of persisting GHD at the end of growth (final height)

\begin{tabular}{llll}
\hline Predictors & OR & $95 \%$ CI & p value \\
\hline IGF-1 <-2 SDS (1-4 months after GH treatment cessation) & 19.3 & $3.6-103.1$ & 0.001 \\
Complete GHD vs. partial GHD at diagnosis & 10.1 & $2.4-42.1$ & 0.001 \\
Pituitary malformation on MRI vs. idiopathic GHD & 5.6 & $1.6-19.4$ & 0.006 \\
Stalk defect/ectopic posterior pituitary vs. idiopathic GHD & 6.5 & $1.1-37.1$ & 0.035 \\
Height gain (by 1 SDS) during treatment & 1.8 & $1.0-3.3$ & 0.048 \\
Sex & 2.29 & $0.72-7.3$ & 0.163 \\
Age at diagnosis & 0.91 & $0.79-1.06$ & 0.224 \\
Bone age retardation (years) & 1 & $0.85-1.17$ & 0.964 \\
Height at diagnosis (SDS) & 0.73 & $0.34-1.59$ & 0.428 \\
Weight at diagnosis (SDS) & 1.04 & $0.73-1.48$ & 0.847 \\
BMI at diagnosis (SDS) & 1.05 & $0.81-1.36$ & 0.723 \\
Puberty retardation (standardized) & 1.04 & $0.79-1.06$ & 0.84 \\
\hline
\end{tabular}

${ }^{a}$ Age at puberty onset - mean age at puberty onset according to Tanner for a reference population.

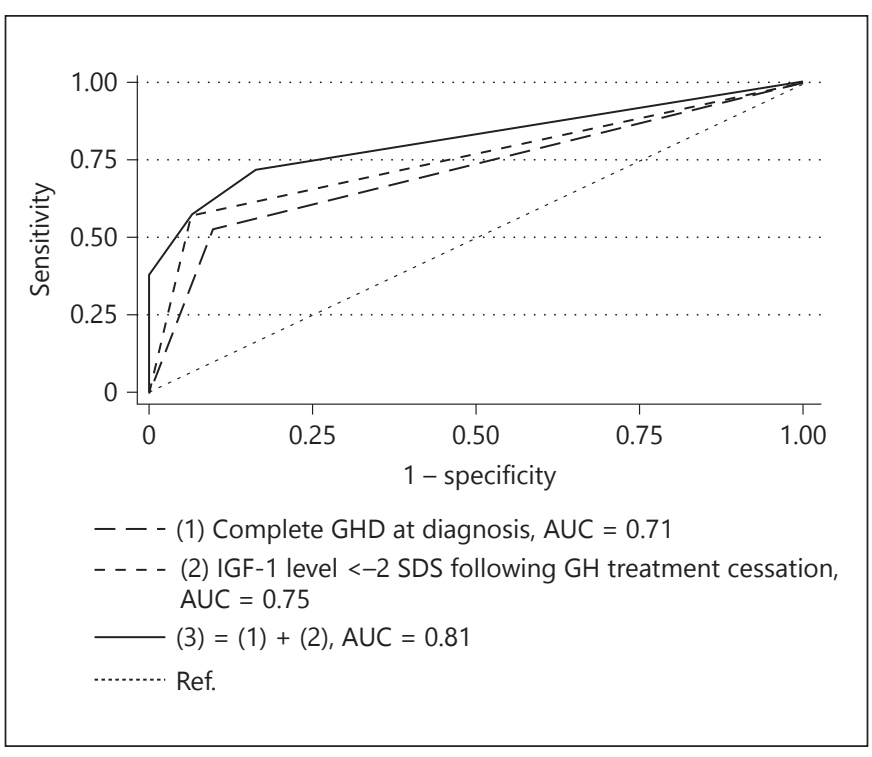

Fig. 3. Diagnostic performance of complete GHD at diagnosis and IGF-1 levels after treatment cessation for predicting persisting GHD at the end of growth (final height). These two predictors have a discrimination power of $81 \%$ (area under the ROC curve $=$ 0.8118 ). Complete GHD defined by peak GH response $<5 \mu \mathrm{g} / \mathrm{l}$ after stimulation. $\mathrm{AUC}=$ Area under the ROC curve.

\section{Discussion}

We studied the natural history of GHD (excluding acquired cases) in a cohort of 63 children. Our retrospective study revealed that $44 \%$ of adolescents remained deficient at the end of growth, while $56 \%$ had recovered. As expected, the majority (89\%) of those ad- olescents who had recovered had partial GHD at diagnosis. Yet, more than half (54\%) of the children with complete GHD improved, with nearly a quarter $(23 \%)$ exhibiting recovery. Furthermore, $8 \%$ of the patients with partial GHD at diagnosis worsened and had complete GHD at reevaluation, but none of these children met the criteria for GH treatment into adulthood. These data suggest a plasticity of the $\mathrm{GH}$ axis among children diagnosed with GHD.

We identified several predictors of persistent GHD in adulthood: IGF-1 <-2 SDS at reassessment (OR 19), complete versus partial GHD at diagnosis (OR 10), pituitary malformations versus idiopathic GHD (OR 5.6), and height gain of $>1$ SDS after treatment (OR 1.8). These findings are clinically important as they can help to direct the assessment of those patients who may require ongoing GHD treatment into adulthood.

This work departs from previous studies in that we excluded acquired GHD and focused exclusively on congenital and idiopathic forms of GHD. The rationale for excluding acquired forms was that the potentially confounding variables introduced by oncological treatment, tumor, or trauma make the interpretation of the natural history data much less clear. Instead, we concentrated on a cohort with potentially, yet likely, genetic etiology underlying GHD.

The retrospective study is limited by the relatively small sample size, as evidenced by quite wide confidence intervals. Therefore, harmonization of stimulation testing and establishing set cutoff values in a prospective multicenter approach seems imperative for future studies to clarify the reassessment of GH status. 
Similar to previous studies, we report a high recovery rate in children with partial GHD [15, 23]. Compared to the study of Tauber et al. [15], including a similar cohort of 131 children with GHD (i.e. peak $\mathrm{GH}<5 \mu \mathrm{g} / \mathrm{l}$ for complete GHD and peak $\mathrm{GH} \geq 5-10 \mu \mathrm{g} / \mathrm{l}$ for partial GHD), we report a slightly lower recovery rate (56 vs. $62 \%)$. This difference may be accounted for by the fact that the previous study included more idiopathic cases (92 vs. 68\%, respectively) and did not include sex steroid priming at the time of puberty. Notably, priming has been suggested by Carel et al. [24] as a means to rule out GHD in children with constitutional growth delay. Our clear predominance of GHD in males compared to females (2:1) (table 2) is consistent with the existing literature [17, 25-27]. Such gender discordance, as in the case of other developmental disorders such as Kallmann syndrome, can potentially be explained by ascertainment bias, i.e. boys are much more likely to present because of short stature than girls. However, the contribution of X-linked genes, epigenetics, or male susceptibility to prenatal or perinatal insult may also be important contributors to this phenomenon.

Importantly, we identified predisposing factors for persistence of GHD, such as IGF-1 levels. Indeed, the relationship between IGF-1 levels and GH peak has been previously demonstrated [15]. Yet, IGF-1 levels $<-2$ SDS have not been shown to be particularly sensitive predictors (46\%), but have a specificity of $100 \%$ (table 1) [16]. Secco et al. [28] evaluated the accuracy of IGF-1 measures in defining permanent GHD. The ROC curve analysis of IGF-1 showed the best diagnostic accuracy with lower IGF-1 levels, i.e. -2.83 SDS (table 1). In contrast, Quigley et al. [27] studied potential predictors of persisting GHD and found that IGF-1 levels did not have a positive predictive value. They proposed using IGF-1 levels $>1.6$ SDS to predict GH sufficiency. The 2 adolescents who recovered with IGF-1 levels $<-2$ SDS in our cohort point to the problem of using only one factor to identify persisting GHD. However, the sensitivity for predicting persisting GHD was improved when an additional factor (complete GHD at diagnosis) was added (fig. 3).

In the present study, gain of height during treatment was identified as a novel predictor of persisting GHD (OR 2 ). As our patients were treated in a dose-adjusted manner, this is consistent with a greater GH treatment effect in those patients with more severe GHD and is in line with a better response to $\mathrm{GH}$ treatment in patients with pituitary imaging abnormalities. Thus, a more severe phenotype may be indicative of GHD persisting into adulthood [25, 27]. However, there is a need for reassessment of this population to identify patients who may recover function.

The recovery rate of $20 \%$ in our patients with ectopic posterior pituitary is similar to rates reported by Gelwane et al. [29] who identified recovery (peak GH $>10 \mu \mathrm{g} / \mathrm{l}$ ) in 6 of $24(25 \%)$ patients with ectopic posterior pituitary. In contrast to prior studies [30,31], we did not find permanent severe GHD in $100 \%$ of patients with pituitary stalk interruption syndrome.

Among those patients with partial GHD at diagnosis, none had a GH peak $<3 \mu \mathrm{g} / \mathrm{l}$ at reassessment, yet 6 of the patients had IGF-1 levels $<-2$ SDS after treatment interruption. Thus, it appears that an IGF-1 level >-2 SDS in a patient with partial GHD would not necessarily require dynamic testing. This would be a novel clinical implication emerging from these data. In effect, such a practice would reduce the number of repeat stimulation tests in young patients diagnosed with partial GHD and should have time- and cost-saving impacts while reducing the risk of adverse testing events.

Despite these novel findings, several important questions relating to $\mathrm{GH}$ reassessment at the end of growth remain unanswered. Salient issues include the optimal test and cutoffs, GH immunoassay sensitivity, and clinical outcomes in patients with or without treatment. Also, the time of retesting warrants further examination, as Darendeliler et al. [23] demonstrated that 69\% of children with partial GHD recover prior to completion of growth. As summarized in table 1, stimulation tests have a huge variability in cutoff values depending on age and test used. The fact that recommendations have changed over time further complicates retrospective interpretations, which explains why we and others have utilized different cutoffs $[15,17]$. Importantly, it remains to be clarified if adopting higher thresholds for stimulated GH peak in young adults could be beneficial for long-term bone health and fracture protection. $\mathrm{GH}$ has important effects on bone formation, particularly cortical thickness [32, 33]. Using appropriate size corrections, bone density in children with isolated GHD is normal [34]. Indeed, supplementation of GH increases bone turnover and increases trabecular bone score reflecting bone remodeling in favor of improving its quality [35]. However, there is yet no clear evidence of increased fracture risk of patients with childhood-onset isolated GHD [10]. Achieving final adult height occurs much earlier than the acquisition of peak bone mass and muscle strength [36]. Accordingly, continuation of $\mathrm{GH}$ treatment at the end of growth could also help op- 
timize muscle development, which may in turn have a positive effect on bone strength and may minimize fracture risk.

During transition, the ITT is the gold standard test. The GH-releasing hormone (GHRH)-ARG test with a similar sensitivity and specificity as shown in table 1 can be used as an alternative, but proposed cutoff values for this test show a high variability that seems to be related to body mass index (BMI) $[16,19]$. The proposed threshold GH value after ITT among young adults is $6.1 \mu \mathrm{g} / \mathrm{l}$ [37]. Using this threshold, more patients would have been identified for $\mathrm{GH}$ treatment at the end of growth (19/50, vs. $4 / 50$ patients). This includes 10 additional patients with partial GHD and 5 patients with complete idiopathic GHD. To identify the cutoff value proposed by Maghnie et al. [38], or more recently the cutoff value of $5.6 \mu \mathrm{g} / \mathrm{l}$ proposed by Secco et al. [28], MPHD and/or pituitary malformation was used as the gold standard to define probable permanent GHD. However, this is not perfect as we and others have demonstrated that patients with pituitary malformation as well as MPHD can recover [17]. In addition, androgen treatment in those GHD patients with pubertal delay may be another important factor. For instance, recovery of hypothalamicpituitary-gonadal axis function has been demonstrated in patients with Kallmann syndrome following sex steroid treatment $[39,40]$. Furthermore, there is a genetic overlap between gonadotropin-releasing hormone (GnRH) deficiency and MPHD [41], thus suggesting a possible molecular basis for the recovery observed in these two developmental endocrine disorders. So, questions regarding an accepted gold standard remain. Further, standardized GH assays with appropriate quality control are critical for interpreting results $[3,11,42]$. Importantly, this aspect has not been given much attention to this point in time and merits consideration when relevant thresholds to guide clinical management are established.

While predictors can be useful in guiding care during the transition period, none of these factors will have a $100 \%$ specificity and sensitivity. Indeed, long-term follow-up of adolescents receiving GH therapy seems appropriately warranted [20]. Additionally, documentation of bone health, BMI, and quality of life will also be a contributing factor to the decision-making process regarding the need for $\mathrm{GH}$ treatment in young adulthood. For example, an increase in body fat and a decreased lean body mass 1 year after GH treatment interruption has been documented in a group of patients with partial GHD [43]. Thus, the clinical pathway for

Natural History of Growth Hormone Deficiency
GHD patients involves numerous important health outcome variables.

The results of our analysis at the end of growth point to several critical questions pertaining to diagnosis in childhood, GH immunoassay sensitivity, and reassessment. In relation to diagnosis, there are a variety of tests used in childhood (i.e. ITT, ARG test, glucagon, etc.) as well as different assays. Indeed, the sensitivity of GH assays has improved over time and the $\mathrm{GH}$ assays that were used to diagnose many of the patients in the present study are not optimal. However, pediatric diagnosis is not solely based on test results but always corroborated with clinical and radiologic findings. Reassessment remains an important question. Secco et al. [28] identified predictors by correlating peak $\mathrm{GH}$ values at diagnosis (albeit using GH assays with suboptimal sensitivity) with outcomes in adulthood. They confirmed that the ITT is an accurate test in the reevaluation of GHD in children at the end of growth and that IGF-1 is a reliable marker for persistence of GHD. These data combined with the present study identify several predictors of persisting GHD in adulthood and underscore remaining questions. Importantly, these predictors should be confirmed by further studies with harmonized testing procedures and standardized cutoffs. Additionally, repeat testing during childhood may help improve the accuracy of diagnosis of GHD, and long-term follow-up is warranted to ensure that those cases of reversal remain normally functioning.

In conclusion, this retrospective study documents the natural history of GHD at the end of growth in a cohort of children with GHD excluding acquired forms. We identified several predictors of persisting GHD at final height: complete GHD at diagnosis, IGF-1 levels $<-2$ SDS following treatment cessation, pituitary malformation on MRI, and greater height gain during $\mathrm{GH}$ treatment. However, important questions remain regarding the continuation of $\mathrm{GH}$ treatment at the end of growth. These data underscore the paucity of data comparing dynamic testing regimens in this population that preclude the development of evidence-based guidelines. We propose using the ITT as the most extensively validated test in young adults during transition. Genetic findings on GHD may provide additional insights into the molecular basis for recovery of adolescents with GHD. Finally, long-term follow-up of these patients evaluating health-related outcomes may also contribute to the decision-making process for continuing $\mathrm{GH}$ treatment. 


\section{References}

1 Vimpani GV, Vimpani AF, Pocock SJ, Farquhar JW: Differences in physical characteristics, perinatal histories, and social backgrounds between children with growth hormone deficiency and constitutional short stature. Arch Dis Child 1981;56:922-928.

-2 Sizonenko PC, Clayton PE, Cohen P, Hintz RL, Tanaka T, Laron Z: Diagnosis and management of growth hormone deficiency in childhood and adolescence. Part 1: diagnosis of growth hormone deficiency. Growth Horm IGF Res 2001;11:137-165.

3 Growth Hormone Research Society: Consensus guidelines for the diagnosis and treatment of growth hormone $(\mathrm{GH})$ deficiency in childhood and adolescence: summary statement of the GH Research Society. GH Research Society. J Clin Endocrinol Metab 2000;85:39903993.

-4 Geffner ME: Growth hormone replacement therapy: transition from adolescence to adulthood. J Clin Res Pediatr Endocrinol 2009;1: 205-208.

5 Gibney J, Wallace JD, Spinks T, Schnorr L, Ranicar A, Cuneo RC, Lockhart S, Burnand KG, Salomon F, Sonksen PH, Russell-Jones $\mathrm{D}$ : The effects of 10 years of recombinant human growth hormone (GH) in adult GH-deficient patients. J Clin Endocrinol Metab 1999;84:2596-2602.

6 Attanasio AF, Shavrikova EP, Blum WF, Shalet SM: Quality of life in childhood onset growth hormone-deficient patients in the transition phase from childhood to adulthood. J Clin Endocrinol Metab 2005;90:45254529.

7 O'Halloran DJ, Tsatsoulis A, Whitehouse RW, Holmes SJ, Adams JE, Shalet SM: Increased bone density after recombinant human growth hormone (GH) therapy in adults with isolated GH deficiency. J Clin Endocrinol Metab 1993;76:1344-1348.

8 Gibney J, Healy ML, Stolinski M, Bowes SB, Pentecost C, Breen L, McMillan C, RussellJones DL, Sonksen PH, Umpleby AM: Effect of growth hormone $(\mathrm{GH})$ on glycerol and free fatty acid metabolism during exhaustive exercise in GH-deficient adults. J Clin Endocrinol Metab 2003;88:1792-1797.

-9 Weaver JU, Monson JP, Noonan K, John WG, Edwards A, Evans KA, Cunningham J: The effect of low dose recombinant human growth hormone replacement on regional fat distribution, insulin sensitivity, and cardiovascular risk factors in hypopituitary adults. J Clin Endocrinol Metab 1995;80: 153-159.

10 Hogler W, Shaw N: Childhood growth hormone deficiency, bone density, structures and fractures: scrutinizing the evidence. Clin Endocrinol 2010;72:281-289.

$\checkmark 11$ Consensus guidelines for the diagnosis and treatment of adults with growth hormone deficiency: summary statement of the Growth Hormone Research Society Workshop on
Adult Growth Hormone Deficiency. J Clin Endocrinol Metab 1998;83:379-381.

12 Carel JC, Ecosse E, Landier F, MeguellatiHakkas D, Kaguelidou F, Rey G, Coste J: Long-term mortality after recombinant growth hormone treatment for isolated growth hormone deficiency or childhood short stature: preliminary report of the French SAGhE study. J Clin Endocrinol Metab 2012; 97:416-425.

13 Savendahl L, Maes M, Albertsson-Wikland K, Borgstrom B, Carel JC, Henrard S, Speybroeck N, Thomas M, Zandwijken G, Hokken-Koelega A: Long-term mortality and causes of death in isolated GHD, ISS, and SGA patients treated with recombinant growth hormone during childhood in Belgium, the Netherlands, and Sweden: preliminary report of 3 countries participating in the EU SAGhE study. J Clin Endocrinol Metab 2012;97:E213E217.

14 Poidvin A, Touze E, Ecosse E, Landier F, Bejot Y, Giroud M, Rothwell PM, Carel JC, Coste J: Growth hormone treatment for childhood short stature and risk of stroke in early adulthood. Neurology 2014;83:780-786.

15 Tauber M, Moulin P, Pienkowski C, Jouret B, Rochiccioli P: Growth hormone $(\mathrm{GH})$ retesting and auxological data in $131 \mathrm{GH}$-deficient patients after completion of treatment. J Clin Endocrinol Metab 1997;82:352-356.

16 Biller BM, Samuels MH, Zagar A, Cook DM, Arafah BM, Bonert V, Stavrou S, Kleinberg DL, Chipman JJ, Hartman ML: Sensitivity and specificity of six tests for the diagnosis of adult GH deficiency. J Clin Endocrinol Metab 2002;87:2067-2079.

17 Leger J, Danner S, Simon D, Garel C, Czernichow P: Do all patients with childhood-onset growth hormone deficiency (GHD) and ectopic neurohypophysis have persistent GHD in adulthood? J Clin Endocrinol Metab 2005;90:650-656.

18 Maghnie M, Aimaretti G, Bellone S, Bona G, Bellone J, Baldelli R, de Sanctis C, Gargantini L, Gastaldi R, Ghizzoni L, Secco A, Tinelli C, Ghigo E: Diagnosis of GH deficiency in the transition period: accuracy of insulin tolerance test and insulin-like growth factor-I measurement. Eur J Endocrinol 2005; 152: 589-596.

19 Corneli G, Di Somma C, Prodam F, Bellone J, Bellone S, Gasco V, Baldelli R, Rovere S, Schneider HJ, Gargantini L, Gastaldi R, Ghizzoni L, Valle D, Salerno M, Colao A, Bona G, Ghigo E, Maghnie M, Aimaretti G: Cut-off limits of the GH response to GHRH plus arginine test and IGF-I levels for the diagnosis of GH deficiency in late adolescents and young adults. Eur J Endocrinol 2007;157: 701-708.

20 Clayton PE, Cuneo RC, Juul A, Monson JP, Shalet SM, Tauber M; European Society of Paediatric Endocrinology: Consensus statement on the management of the GH-treated adolescent in the transition to adult care. Eur J Endocrinol 2005; 152:165-170.

21 Hartman ML, Crowe BJ, Biller BM, Ho KK, Clemmons DR, Chipman JJ; HyposCCS Advisory Board; US HypoCCS Study Group: Which patients do not require a GH stimulation test for the diagnosis of adult GH deficiency? J Clin Endocrinol Metab 2002;87: 477-485.

22 Elmlinger MW, Kuhnel W, Weber MM, Ranke MB: Reference ranges for two automated chemiluminescent assays for serum insulinlike growth factor I (IGF-I) and IGF-binding protein 3 (IGFBP-3). Clin Chem Lab Med 2004;42:654-664.

23 Darendeliler F, Spinu I, Bas F, Bundak R, Isguven P, Arslanoglu I, Saka N, Sukur M, Gunoz H: Reevaluation of growth hormone deficiency during and after growth hormone (GH) treatment: diagnostic value of $\mathrm{GH}$ tests and IGF-I and IGFBP-3 measurements. J Pediatr Endocrinol Metab 2004;17:10071012.

24 Carel JC, Ecosse E, Coste J: Growth hormone in growth hormone deficiency. Ignore the evidence and keep going wrong. BMJ 2002;325: 1037.

25 Deal C, Hasselmann C, Pfaffle RW, Zimmermann AG, Quigley CA, Child CJ, Shavrikova EP, Cutler GB Jr, Blum WF: Associations between pituitary imaging abnormalities and clinical and biochemical phenotypes in children with congenital growth hormone deficiency: data from an international observational study. Horm Res Paediatr 2013;79:283292.

26 Hughes IP, Choong CS, Cotterill A, Harris M, Davies PS: Gender bias in children receiving growth hormone treatment. J Clin Endocrinol Metab 2010;95:1191-1198.

27 Quigley CA, Zagar AJ, Liu CC, Brown DM, Huseman C, Levitsky L, Repaske DR, Tsalikian E, Chipman JJ: United States multicenter study of factors predicting the persistence of $\mathrm{GH}$ deficiency during the transition period between childhood and adulthood. Int J Pediatr Endocrinol 2013;2013:6.

28 Secco A, di Iorgi N, Napoli F, Calandra E, Calcagno A, Ghezzi M, Frassinetti C, Fratangeli N, Parodi S, Benassai M, Leitner Y, Gastaldi R, Lorini R, Maghnie M, Radetti G: Reassessment of the growth hormone status in young adults with childhood-onset growth hormone deficiency: reappraisal of insulin tolerance testing. J Clin Endocrinol Metab 2009;94: 4195-4204.

29 Gelwane G, Garel C, Chevenne D, Armoogum P, Simon D, Czernichow P, Leger J: Subnormal serum insulin-like growth factor-I levels in young adults with childhood-onset nonacquired growth hormone $(\mathrm{GH})$ deficiency who recover normal GH secretion may indicate less severe but persistent pituitary failure. J Clin Endocrinol Metab 2007;92:37883795. 
30 Hilczer M, Smyczynska J, Stawerska R, Lewinski A: Final height and growth hormone secretion after completion of growth hormone therapy in patients with idiopathic growth hormone deficiency and with abnormalities of the hypothalamic-pituitary region. Neuro Endocrinol Lett 2005;26:19-24.

31 Murray PG, Hague C, Fafoula O, Gleeson H, Patel L, Banerjee I, Raabe AL, Hall CM, Wright NB, Amin R, Clayton PE: Likelihood of persistent GH deficiency into late adolescence: relationship to the presence of an ectopic or normally sited posterior pituitary gland. Clin Endocrinol 2009;71:215-219.

- 32 Hyldstrup L, Conway GS, Racz K, Keller A, Chanson P, Zacharin M, Lysgaard AL, Andreasen AH, Kappelgaard AM: Growth hormone effects on cortical bone dimensions in young adults with childhood-onset growth hormone deficiency. Osteoporos Int 2012;23: 2219-2226.

-33 Andreassen TT, Jorgensen PH, Flyvbjerg A, Orskov H, Oxlund H: Growth hormone stimulates bone formation and strength of cortical bone in aged rats. J Bone Miner Res 1995;10: 1057-1067.

34 Baroncelli GI, Bertelloni S, Galli L, Sodini F, Saggese G: Cortical bone density is normal in prepubertal children with growth hormone (GH) deficiency, but initially decreases during $\mathrm{GH}$ replacement due to early bone remodeling. J Clin Endocrinol Metab 2004;89:2505; author reply 2505-2506.
35 Kuzma M, Kuzmova Z, Zelinkova Z, Killinger Z, Vanuga P, Lazurova I, Tomkova S, Payer J: Impact of the growth hormone replacement on bone status in growth hormone deficient adults. Growth Horm IGF Res 2014;24:22-28.

- 36 Bonjour JP, Theintz G, Buchs B, Slosman D, Rizzoli R: Critical years and stages of puberty for spinal and femoral bone mass accumulation during adolescence. J Clin Endocrinol Metab 1991;73:555-563.

37 Ho KK; 2007 GH Deficiency Consensus Workshop Participants: Consensus guidelines for the diagnosis and treatment of adults with GH deficiency II: a statement of the GH Research Society in association with the European Society for Pediatric Endocrinology, Lawson Wilkins Society, European Society of Endocrinology, Japan Endocrine Society, and Endocrine Society of Australia. Eur J Endocrinol 2007; 157:695-700.

38 Maghnie M, Strigazzi C, Tinelli C, Autelli M, Cisternino M, Loche S, Severi F: Growth hormone (GH) deficiency (GHD) of childhood onset: reassessment of GH status and evaluation of the predictive criteria for permanent GHD in young adults. J Clin Endocrinol Metab 1999;84:1324-1328.
39 Sidhoum VF, Chan YM, Lippincott MF, Balasubramanian R, Quinton R, Plummer L, Dwyer A, Pitteloud N, Hayes FJ, Hall JE, Martin KA, Boepple PA, Seminara SB: Reversal and relapse of hypogonadotropic hypogonadism: resilience and fragility of the reproductive neuroendocrine system. J Clin Endocrinol Metab 2014;99:861-870.

40 Raivio T, Falardeau J, Dwyer A, Quinton R, Hayes FJ, Hughes VA, Cole LW, Pearce SH, Lee H, Boepple P, Crowley WF Jr, Pitteloud N: Reversal of idiopathic hypogonadotropic hypogonadism. N Engl J Med 2007;357:863-873.

41 Raivio T, Avbelj M, McCabe MJ, Romero CJ, Dwyer AA, Tommiska J, Sykiotis GP, Gregory LC, Diaczok D, Tziaferi V, Elting MW, Padidela R, Plummer L, Martin C, Feng B, Zhang C, Zhou QY, Chen H, Mohammadi M, Quinton R, Sidis Y, Radovick S, Dattani MT, Pitteloud N: Genetic overlap in Kallmann syndrome, combined pituitary hormone deficiency, and septo-optic dysplasia. J Clin Endocrinol Metab 2012;97:E694-E699.

42 Bidlingmaier M, Strasburger CJ: Growth hormone assays: current methodologies and their limitations. Pituitary 2007;10:115-119.

43 Tauber M, Jouret B, Cartault A, Lounis N, Gayrard M, Marcouyeux C, Pienkowski C, Oliver I, Moulin P, Otal P, Joffre F, Arnaud C, Rochiccioli P: Adolescents with partial growth hormone (GH) deficiency develop alterations of body composition after GH discontinuation and require follow-up. J Clin Endocrinol Metab 2003;88:5101-5106. 